\title{
Myocarditis and fulminant hepatic failure from coxsackievirus B infection
}

\author{
R.B. Read, R.J. Ede, P. Morgan-Capner, G. Moscoso, B. Portmann and \\ Roger Williams
}

Liver Unit and Department of Microbiology, King's College School of Medicine and Dentistry, Denmark Hill, London SE5 8RX, UK.

\begin{abstract}
Summary: A case of fulminant hepatic failure in association with myocarditis is reported. Presentation suggested an acute hepatitis which was complicated by cardiac failure. Evidence of severe myocarditis was found at autopsy.
\end{abstract}

\section{Introduction}

Coxsackievirus B is an uncommon cause of hepatitis (Public Health Laboratory Service, 1967; Lau, 1983) with severe cases having been recorded only occasionally in adults (Sun \& Smith, 1966; O'Shaughnessey \& Buechner, 1962; Gregor et al., 1975), although no instance of true fulminant hepatic failure (FHF) from this cause has, to our knowledge, been described. In the present report we describe a patient with coxsackievirus $B$ infection and fulminant hepatic failure in association with a severe myocarditis. The evidence for coxsackievirus B infection was an elevation in neutralizing antibody titres and the detection of coxsackievirus B IgM antibody in the serum.

\section{Case history}

A 16 year old, previously well, woman presented to hospital following a 2 week illness of vomiting, abdominal pain, general malaise and 1 week of increasing jaundice. Over the $48 \mathrm{~h}$ following admission, hypotension and anuria developed. There had been no previous history of liver disease nor any recent exposure to drugs or contacts with jaundiced persons. The presence of a high central venous pressure, cardiomegaly and hypotension was thought to be due to a pericardial effusion but no pericardial fluid could be obtained on needle aspiration. At this stage the patient was transferred to the Liver Unit, King's College Hospital for further management. On arrival she was deeply jaundiced with signs of grade II hepatic encephalopathy. The liver was palpable $3 \mathrm{~cm}$ below the costal margin but there was no evidence of chronic

Correspondence: R. Williams, M.D., F.R.C.P.

Accepted: 28 February 1985 liver disease. Blood pressure was $90 / 70 \mathrm{~mm} \mathrm{Hg}$, pulse $80 /$ min and cardiac monitor showed sinus rhythm.

Following insertion of a Swan-Ganz catheter the following values were obtained: right heart central venous pressure $26 \mathrm{~mm} \mathrm{Hg}$, pulmonary artery wedge pressure $21 \mathrm{~mm} \mathrm{Hg}$ and cardiac index $1.91 / \mathrm{min} / \mathrm{m}^{2}$. Arterial blood gases: $\mathrm{pH} 7.28, \mathrm{PO}_{2} 21.8 \mathrm{kPa}$, $\mathrm{PCO}_{2} 1.17 \mathrm{kPa}$ and base excess $(\mathrm{BE})-20$. Chest X-ray showed a globular heart and pulmonary oedema. Further laboratory investigations confirmed severe hepatocellular damage and renal failure: serum aspartate aminotransferase 2,351 IU/l, bilirubin $126 \mu \mathrm{mol} / 1$, prothrombin time $86 \mathrm{~s}$ prolonged over control, serum creatinine $417 \mu \mathrm{mol} / 1$, urea $36 \mathrm{mmol} / 1$. Serum amylase activity was normal. White cell count 10,200 with a normal differential.

A clinical diagnosis of fulminant hepatic failure with secondary renal failure was made and because of the presence of hypotension a complicating septicaemia was suspected. She was commenced on cefuroxime $750 \mathrm{mg}$ t.d.s. and was haemodialysed with a polyacrylonitrile membrane. The level of hepatic encephalopathy deteriorated to grade IV and she developed signs of cerebral oedema which was treated with bolus doses of $20 \%$ mannitol $(1 \mathrm{~g} / \mathrm{kg})$. In view of the elevated pulmonary artery wedge pressure, ultrafiltration was performed during dialysis and a total volume of 7.2 litres was removed on two separate occasions. Following the second dialysis the patient became lucid and coherent, arterial blood gases and serum electrolytes were within normal limits but the pulmonary artery wedge pressure, which had fallen to $24 \mathrm{~mm} \mathrm{Hg}$ during dialysis, rose to $30 \mathrm{~mm} \mathrm{Hg}$. Ventricular fibrillation occurred unexpectedly and, although initially resuscitated, the patient remained profoundly hypotensive and died $24 \mathrm{~h}$ after admission. 


\section{Laboratory findings}

Blood cultures were sterile and hepatitis B surface antigen (HBsAg), hepatitis A IgM antibody and heterophil antibody were not detected. No raised titres were detected by complement fixation testing for antibodies to cytomegalovirus, leptospira, herpes simplex, adenovirus or mumps. However, sera collected 3 days before transfer and on arrival at King's College Hospital showed the following neutralization titres to the 6 types of coxsackievirus B: B1 1:40; B2 1:1280; B3 1:80; B4 1:640; B5 <1:40; B6 <1:40. These neutralization titres detect antibodies of both the IgG and IgM class. Since only the IgM antibody is indicative of recent or recurrent infection both sera were also assayed for coxsackievirus B IgM using an IgM capture radioimmunoassay (MACRIA) which used a pooled coxsackievirus B1-5 as antigen (Morgan-Capner \& McSorley, 1983). The sera were compared with a low positive control serum, where previous evaluation of enterovirus-specific IgM positive and negative sera had shown that results in excess of $75 \%$ of the low positive serum were indicative of enterovirus-specific IgM. The values obtained from the two sera from this patient were $116 \%$ and $110 \%$ respectively.

\section{Autopsy findings}

The liver was shrunken and weighed only $665 \mathrm{~g}$ with a red mottled appearance on the cut surface corresponding histologically to confluent areas of necrosis and congestion involving the whole of zone 3 of liver acini and extending, in some places, to zone 2 (Figure 1). In some areas there was evidence of hepatocyte dropout

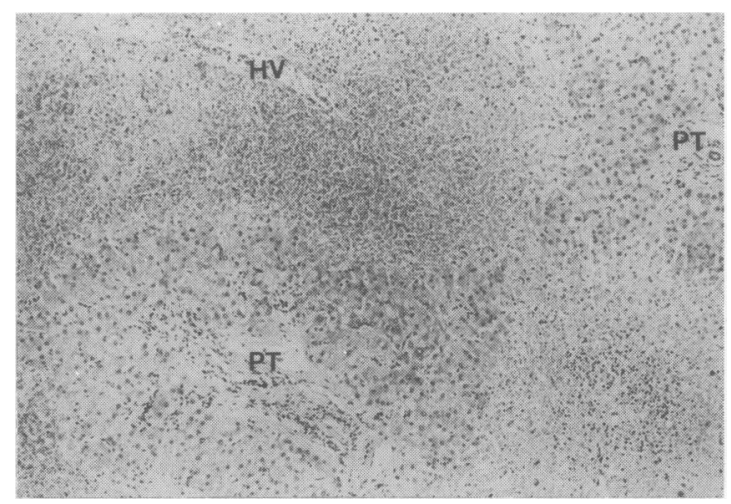

Figure 1 Liver histology. There are extensive areas of confluent hepatocyte loss with severe terminal congestion and mild, mixed, inflammatory cell infiltration. Portal tract (PT); hepatic venule (HV), H \& E $\times 80$. with reticulin collapse and mixed cell infiltrates which included pigmented macrophages, whereas more recent coagulative necrosis was observed in other places. The mixed inflammatory cells were scattered mainly within necrotic areas and were scanty or absent within normal sized portal tracts.

The heart was globular, weighed $420 \mathrm{~g}$ and had a flabby consistency with prominent petechial haemorrhages on the epicardial surface. Both cavities were dilated. A post-mortem coronary arteriogram showed no evidence of coronary artery disease. On histological examination sections from right, left and interventricular myocardium showed variable degrees of necrosis and loss of myocardial fibres with loose fibrous tissue proliferation and profuse focal cell infiltrates composed predominantly of lymphocytes, macrophages and plasma cells (Figure 2). Individual myocytes were variably swollen with granular degeneration and loss of striation or were atrophic with contraction bands within the cytoplasm. There were also isolated necrotic cells in the left bundle of the conduction system.

\section{Discussion}

Uncommon viral causes of FHF (excluding hepatitis A, B and non-A, non-B) are Epstein-Barr virus (Davies et al., 1980), herpes simplex, echovirus (Hughes et al., 1972) and cytomegalovirus. Coxsackievirus $B$ infection occurs most commonly in children and young adults and usually causes an asymptomatic or self-limiting febrile illness without distinctive features. Complete recovery is usual except in newborn infants or in older patients who have one of the well-defined syndromes associated with this virus, of

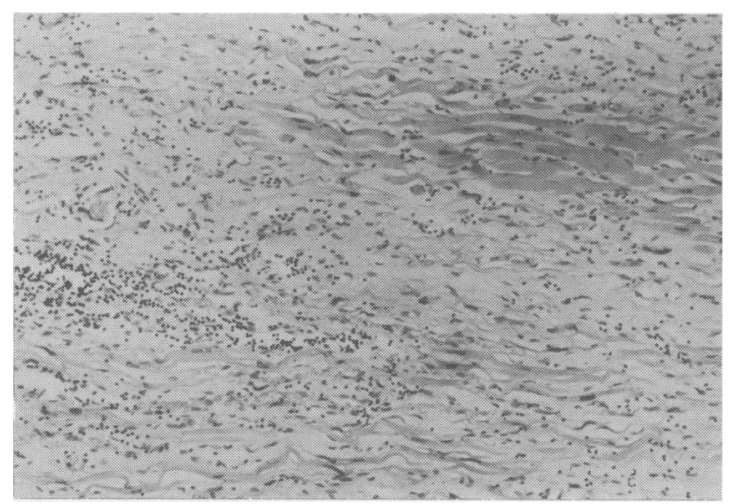

Figure 2 Acute myocarditis. Severely damaged and sparse myocytes are set in a loose connective tissue containing collections of lymphocytes. H \& $\mathrm{E} \times 125$. 
which aseptic meningitis, epidemic myalgia and myocarditis are the most common. Hepatitis due to coxsackievirus B infection is rare in adults (Lau 1983; Public Health Laboratory Service 1967) and even in the most severe case reported (Gregor et al., 1975) there was no definite evidence of hepatic encephalopathy. FHF has, however, been reported in at least four children with coxsackievirus $B$ infection and possibly in five others (Bernirschke et al., 1958; Newton \& Hosier, 1958).

The clinical presentation of the patient we report was of an acute viral-like hepatitis progressing to FHF, with a 2 week prodromal illness, increasing jaundice and prolongation of prothrombin time together with the appearance and rapid progression of hepatic encephalopathy. The histological changes in the liver were similar to those seen in neonates dying from severe cardiac and liver disease due to coxsackievirus B infection (Benirschke et al., 1958).

The extent to which the liver damage was the result of hepatitis or of severe cardiac failure is uncertain. The small size of the liver is more in keeping with a fulminant viral hepatitis but the paucity of inflammatory cell infiltrate in the liver and the sharp delineation of the necrotic areas favour an ischaemic aetiology. FHF as a consequence of severe cardiac failure is very uncommon and only 16 cases had been documented in the world literature by 1980 , most of whom had been profoundly hypotensive prior to the onset of liver failure (Nouel et al., 1980). In a recent series of 324 patients with FHF admitted to this Unit there was not a single case in which FHF was secondary to this cause (Gimson et al., 1982).

In a study of the cardiac abnormalities in FHF, Weston et al. (1976) demonstrated macroscopic abnormalities at autopsy in 42 of the $76(55 \%)$ hearts examined. In that series the main abnormalities were scattered petechial haemorrhages, pale fatty myocardium, dilation of the ventricles without other organic cause and pericardial effusion. These changes were as common in patients with FHF due to paracetamol overdose as they were in those with a viral aetiology and this suggests they were a consequence of the liver failure. However, in the case we report, the striking feature at autopsy was the severe myocarditis with almost complete myocardial necrosis and profuse inflammatory cell infiltrate. The presence of low cardiac output early in the course of her illness and the persistently raised pulmonary artery wedge pressure despite haemodialysis and ultrafiltration were further evidence of the severe cardiac involvement.

The detection of coxsackievirus B IgM antibody is evidence of possible coxsackievirus B infection, although the degree of cross-reactivity seen in such assays with sera from patients with other enterovirus infections, such as coxsackievirus A or echovirus, mean that a positive result is only indicative of a recent or current enterovirus infection (Morgan-Capner \& McSorley, 1983). Although no specimens for virus isolation were obtained during life or at post-mortem, the serology is highly suggestive of coxsackievirus B infection. Neutralization antibody titres of the level seen in this patient are uncommon except in association with a recent infection.

\section{Acknowledgements}

We thank Dr D.R. Gamble of the Public Health Laboratory, Epsom, for performing the coxsackievirus B neutralization titres.

\section{References}

BENIRSCHKE, K., KIBRICK S. \& CRAIG, J.M. (1958). The pathology of fatal coxsackie infection in the newborn. Proceedings of the Fifty-fifth Annual Meeting of the American Association of Pathologists and Bacteriologists. American Journal of Pathology, 34, 587.

DAVIES, M.H., MORGAN-CAPNER, P., PORTMANN, B., WILKINSON, S.P. \& WILLIAMS, R. (1980). A fatal case of Epstein-Barr virus infection with jaundice and renal failure. Postgraduate Medical Journal, 56, 794-5.

GIMSON, A.E.S., EDE, R.J., BRAUDE, S., HUGHES, R.D., LANGLEY, P.J. \& WILLIAMS, R. (1982). Fulminant hepatic failure and artificial liver support. Gastroenterologica Japonica, 17, 144.

GREGOR, G.R., GELLER, S.A., WALKER, G.F. \& CAMPOMANES, B.A. (1975). Coxsackie hepatitis in an adult, with ultrastructural demonstration of the virus. Mount Sinai Journal of Medicine, 42, 575.

HUGHES, J.R., WILFERT, C.M., MOORE, M., BENIRSCHKE, K. \& DE HOYOS-GUEVARA, E. (1972). Echovirus 14

infection associated with fatal neonatal hepatic necrosis. American Journal of Diseases in Childhood, 123, 61.

LAU, R.C.H. (1983). Coxsackie B virus infection in New Zealand patients with cardiac and non-cardiac diseases. Journal of Medical Virology, 11, (2), 131.

MORGAN-CAPNER, P. \& MCSORLEY, C. (1983). Antibody capture radioimmunoassay (MACRIA) for coxsackievirus B4 and B5 specific IgM. Journal of Hygiene, 90, 333.

NEWTON, W. \& HOSIER, D.M. (1958). Coxsackie infection in infants and children: focal disseminated; fatal and nonfatal. Proceedings of the Fifty-fifth Annual Meeting of the American Association of Pathologists and Bacteriologists. American Journal of Pathology, 34, 587.

NOUEL, O., HENRION, J., BERNUAU, J., DEGOTT, C., RUEFF, B. \& BENHAMOU, J.P. (1980). Fulminant hepatic failure due to transient circulatory failure in patients with chronic heart disease. Digestive Diseases and Sciences, 26, 49.

O'SHAUGHNESSEY, W.J. \& BUECHNER, H.A. (1962). 
Hepatitis associated with coxsackie B5 virus infection during late pregnancy. Journal of the American Medical Association, 179, 71.

PUBLIC HEALTH LABORATORY SERVICE: COXSACKIE B5 VIRUS INFECTION SURVEY 1965 (1967). British Medical Journal, 4, 575.

SUN, N.C. \& SMITH, V.M. (1966). Hepatitis associated with myocarditis. Unusual manifestations of infection with coxsackie virus group B, type 3. New England Journal of Medicine, 274, 190.

WESTON, M.J., TALBOT, I.C., HOWORTH, P.J.N., MANT, A.K., CAPILDEO, R. \& WILLIAMS, R. (1976). Frequency of arrhythmias and other cardiac abnormalities in fulminant hepatic failure. British Heart Journal, 38, 1179. 